\title{
Safety and efficacy of dual therapy with GSK233705 and salmeterol versus monotherapy with salmeterol, tiotropium, or placebo in a crossover pilot study in partially reversible COPD patients
}

This article was published in the following Dove Press journal: International Journal of COPD

2 March 2012

Number of times this article has been viewed

Jutta Beier'

Jan van Noord ${ }^{2}$

Amanda Deans ${ }^{3}$

Jean Brooks ${ }^{3}$

Claire Maden ${ }^{3}$

Suus Baggen ${ }^{4}$

Rashmi Mehta ${ }^{5}$

Anthony Cahn ${ }^{3}$

'INSAF Respiratory Research Institute, Germany; ${ }^{2}$ Atrium

Medisch Centrum, The Netherlands; ${ }^{3}$ GlaxoSmithKline, Stockley Park,

UK; ${ }^{4}$ GlaxoSmithKline, Zeist, The

Netherlands; ${ }^{5} \mathrm{GlaxoSmithKline,} \mathrm{RTP,}$ NC, USA
Correspondence: Jutta Beier INSAF Respiratory Research Institute, Institut für Atemwegsforschung,

Biebricher Allee 34, 65I87

Wiesbaden, Germany

$\mathrm{Tel}+4961$ I 9854410

Fax +49 6II 9854348

Email j.beier@insaf-wi.de
Background: GSK233705 is an inhaled, long-acting muscarinic antagonist in development for the treatment of chronic obstructive pulmonary disease (COPD). This study was performed to see if the addition of GSK233705 to salmeterol would provide greater bronchodilation than salmeterol or tiotropium alone in COPD.

Methods: In an incomplete-block, three-period, crossover design, dually responsive patients received three of the following five treatments: GSK233705 $20 \mu \mathrm{g}$ plus salmeterol $50 \mu \mathrm{g}$ twicedaily; GSK233705 $50 \mu \mathrm{g}$ plus salmeterol $50 \mu \mathrm{g}$ twice-daily; salmeterol $50 \mu \mathrm{g}$ or placebo, each twice-daily; and tiotropium $18 \mu \mathrm{g}$ or placebo once-daily for 7 days. Each treatment period was separated by a 14-day washout. The primary efficacy endpoint was morning (trough) forced expiratory volume in 1 second $\left(\mathrm{FEV}_{1}\right)$ on Day 8 , following 7 days of treatment. Secondary endpoints included pulmonary function, plethysmography, pharmacokinetics of GSK233705 and salmeterol, adverse events (AEs), electrocardiograms (ECGs), vital signs, and laboratory parameters.

Results: A total of 47 patients were randomized. The mean \% predicted normal postbronchodilator $\mathrm{FEV}_{1}$ was $55 \%$ at screening. Compared with placebo $(\mathrm{n}=24)$, the adjusted mean change from baseline in trough $\mathrm{FEV}_{1}$ on Day 8 was $215 \mathrm{~mL}$ higher with GSK233705 $20 \mu \mathrm{g}+\operatorname{salmeterol}(\mathrm{n}=23)$ and $203 \mathrm{~mL}$ higher with GSK233705 $50 \mu \mathrm{g}+$ salmeterol $(\mathrm{n}=27)$, whereas with salmeterol $(\mathrm{n}=27)$ and tiotropium $(\mathrm{n}=28)$ the changes were $101 \mathrm{~mL}$ and $118 \mathrm{~mL}$ higher, respectively. The primary efficacy results were supported by the results from the other secondary lung function assessments. AEs were reported by similar proportions of patients across the treatment groups, with headache the most frequently reported treatment-related $\mathrm{AE}$ reported by one subject receiving each of GSK233705 $20 \mu \mathrm{g}+$ salmeterol, tiotropium, and placebo. No significant differences were seen in vital signs, ECGs, or laboratory parameters between the groups.

Conclusion: The addition of GSK233705 to salmeterol in partially reversible COPD patients resulted in greater bronchodilation than salmeterol or tiotropium alone and was well tolerated.

Keywords: COPD, bronchodilation, dual therapy, LAMA, LABA

\section{Background}

Bronchodilators are the cornerstone of the symptomatic management of COPD and current Global initiative for chronic Obstructive Lung Disease guidelines recommend 
the use of long-acting inhaled bronchodilators in moderate to very severe COPD. ${ }^{1,2}$ The benefits of bronchodilators include not only the control of symptoms but also improvements in lung function, hyperinflation, exercise performance, exacerbation rate, and health status.

Long-acting inhaled bronchodilators include both long-acting $\beta$-agonists (LABA), such as formoterol or salmeterol, and long-acting muscarinic antagonists (LAMA), such as tiotropium bromide. For patients who are not sufficiently controlled on maintenance monotherapy, combining bronchodilators of different classes, in particular a LAMA and a LABA, has been advocated. ${ }^{3}$ LABA/LAMA combinations appear to play an important role in maximizing bronchodilation and are well tolerated by the majority of patients. $^{4-8}$

The scientific rationale for combining a LABA and muscarinic antagonist in COPD has been reviewed by several authors. ${ }^{9,10}$ Complementary bronchodilation may be obtained either by directly relaxing the smooth muscle through stimulation of $\beta 2$ adrenoceptors or by inhibiting the action of acetylcholine at muscarinic receptors with muscarinic antagonists, indirectly leading to smooth muscle relaxation. Most studies published to date have reported the use of a combination of a twice-daily LABA with tiotropium $^{4-8,11,12}$ or twice-daily LABA with short-acting muscarinic antagonists. ${ }^{13,14}$

There are a number of LAMAs in clinical development as monotherapies and in fixed combinations with LABAs. ${ }^{9,10}$ GlaxoSmithKline (GSK) are also developing novel LAMAs and one such compound is twice-daily GSK233705, also known as darotropium, a high-affinity pan-active muscarinic receptor antagonist (data on file). Phase I and II studies have assessed the efficacy, safety, tolerability, pharmacodynamics, and pharmacokinetics of single and repeat doses of GSK233705 and shown it to be generally well tolerated and an effective bronchodilator.

This pilot study in COPD patients responsive to both $\beta$-agonists and antimuscarinics was performed to see if the addition of GSK233705 to salmeterol would provide greater bronchodilation than salmeterol or tiotropium alone.

\section{Methods}

\section{Patients and methods}

Patients were recruited between October 2006 and May 2007 at nine centers in Finland, Germany, the Netherlands, and the UK. All patients gave written informed consent and the protocol was approved by the appropriate institutional review boards and conducted in accordance with good clinical practice guidelines and the most recent version of the Declaration of Helsinki. Patients aged 40-75 years with a clinical history of COPD according to the American Thoracic Society/European Respiratory Society (ATS/ERS) definition, ${ }^{2}$ a smoking history of $\geq 10$ pack years, a postbronchodilator forced expiratory volume in 1 second $\left(\mathrm{FEV}_{1}\right)$ of $\geq 40 \%$ to $\leq 75 \%$ of predicted normal, and a postbronchodilator $\mathrm{FEV}_{1} /$ forced vital capacity $(\mathrm{FVC})$ ratio of $\leq 70 \%$ were recruited. In order to recruit the optimum patient population for the study, patients also had to demonstrate responsiveness/reversibility to both $80 \mathrm{mcg}$ ipratropium bromide and $400 \mathrm{mcg}$ salbutamol. Responsiveness/Reversibility was defined as an increase in $\mathrm{FEV}_{1}$ of $\geq 12 \%$ and $\geq 150 \mathrm{~mL}$ following inhalation of each bronchodilator administered on different occasions. Subjects with very large improvements in $\mathrm{FEV}_{1}>500 \mathrm{~mL}$ at testing were excluded as this suggested the possibility of an alternative diagnosis.

Patients were excluded from the study if they had suffered a COPD exacerbation, had changes in COPD medication, or taken antibiotics within 4 weeks prior to screening or during the run-in period. Patients were also excluded if they had: a current diagnosis of asthma, a history of asthma, known respiratory disorders (apart from COPD), previous lung surgery, or required long-term oxygen therapy or pulmonary rehabilitation at screening. Patients were excluded if they had significant unstable cardiovascular disease.

\section{Study design}

This was a multicenter, randomized, partially blinded (active versus placebo treatment), placebo-controlled, three-way crossover study. Each subject was randomized to receive three of a possible five treatments (incomplete block design). The five treatments were: GSK233705 $20 \mu \mathrm{g}$ plus salmeterol $50 \mu \mathrm{g}$ twice-daily; GSK233705 $50 \mu \mathrm{g}$ plus salmeterol $50 \mu \mathrm{g}$ twice-daily; salmeterol $50 \mu \mathrm{g}$ twice-daily; tiotropium bromide $18 \mu \mathrm{g}$ once daily; and placebo (GSK study number AC2106956; clinical trials.gov NCT00422604). ${ }^{15}$ After a 2-week run-in period to establish a stable baseline, subjects were randomized to treatment sequences which comprised three 7-day treatment periods, each separated by a 14-day wash-out period. Two types of inhaler were used for the study (Diskus/Accuhaler ${ }^{\mathrm{TM}}$ [GlaxoSmithKline, London, UK] for GSK233705, salmeterol, and placebo and HandiHaler ${ }^{\mathrm{TM}}$ [Boehringer Ingelheim, Ingelheim am Rhein, Germany] for tiotropium bromide and placebo). 


\section{Concomitant medication}

Inhaled salbutamol was provided as a relief medication. Other permitted medications included inhaled corticosteroids at a dose of up to $1000 \mu \mathrm{g}$ /day of fluticasone propionate or equivalent (provided the dose had remained constant for 6 weeks prior to screening and would remain constant throughout the study). Patients who were taking LABA/ICS combination treatments had the LABA component stopped and replaced by the equivalent dose of inhaled corticosteroid (ICS) as monotherapy.

\section{Outcome measurements}

Lung function was determined by measuring the spirometry parameters $\mathrm{FEV}_{1}$ and $\mathrm{FVC}$, and the plethysmography parameters airway conductance (sGaw), airways resistance (Raw), inspiratory capacity (IC), and residual volume (RV). Both trough (measured before the morning dose on Day 2 and Day 8) and postdose (measured on Day 1 and Day 7) spirometry and plethysmography values were recorded with plethysmography assessments conducted after spirometry. Serial spirometry was performed on Day 1 and Day 7 of each treatment period predose and at 1, 2, 4, 9, 12, and 24 hours following the morning dose of study medication. Plethysmography was performed predose and at 3, 11, and 25 hours postdose on Day 1 and Day 7. Subjects also recorded morning peak expiratory flow (PEF) prior to the morning dose of study medication and relief salbutamol rescue use on daily record cards during the run-in, wash-out, and treatment periods.

The primary efficacy endpoint was morning predose (trough) $\mathrm{FEV}_{1}$ on Day 8, following 7 days of treatment. Secondary lung function endpoints included trough $\mathrm{FEV}_{1}$ on Day 2; postdose $\mathrm{FEV}_{1}$, FVC, and plethysmography measurements on Day 1 and Day 7; trough FVC and trough plethysmography measurements on Day 2 and Day 8; and morning predose PEF and rescue medication recorded on the daily record card.

Safety endpoints included the incidence of adverse events (AEs), incidence of COPD exacerbations, vital signs (systolic and diastolic blood pressure and heart rate), and clinical laboratory tests (hematology, chemistry, and urinalysis). In addition, 12-lead electrocardiograms (ECGs) and 24-hour Holter monitoring were conducted during the study. Vital signs and 12-lead ECGs were measured at 15 and 45 minutes, 2, 4, 8, and 24 hours postdose on Day 1 and 7 of each treatment period. Lead II ECG monitoring was performed for 6 hours postdose at each treatment visit.

\section{Pharmacokinetic assessments}

Blood samples were collected to determine plasma concentrations of GSK233705 and salmeterol predose, 5,15 , and 30 minutes, and 1 hour and 2 hours postdose on Day 1. On Day 7, samples were collected as for Day 1 plus additional samples at 4 and 12 hours. Plasma samples were analyzed for GSK233705 and salmeterol using a validated analytical method based on protein precipitation, followed by high-performance liquid chromatography with mass spectrometry. The lower limit of quantification was $0.01 \mathrm{ng} / \mathrm{mL}$ for GSK233705 and $0.025 \mathrm{ng} / \mathrm{mL}$ for salmeterol. Urine samples were also analyzed for GSK233705 using a validated analytical method based on dilution followed by high-performance liquid chromatography with mass spectrometry analysis.

\section{Statistical analysis}

The sample size was based on estimates of precision of the anticipated treatment differences in $\mathrm{FEV}_{1}$, rather than formal powering, since this was a preliminary hypothesis-generating study. Three analysis populations were used. The modified per protocol (MPP) population, which comprised all subjects who completed at least one posttreatment lung-function assessment in at least two treatment periods and in which major deviations from the protocol did not occur, was used to analyze efficacy. The safety population included all subjects who were randomized and had received at least one dose of study medication and was used for all safety summaries and analyses, background, and demography summaries. Analyses of vital signs and 12-lead ECG data included all subjects in the safety population who recorded a posttreatment value for the relevant parameter in at least two treatment periods. The pharmacokinetic (PK) concentration population comprised all subjects in the safety population for whom a PK sample was obtained and analyzed.

The primary comparison for which treatment differences were estimated was of each dose of GSK233705 plus salmeterol versus placebo. Secondary comparisons for which treatment differences were estimated were for each dose of GSK233705 plus salmeterol versus salmeterol alone or tiotropium. Trough FEV, values on Day 2 and Day 8 were analyzed using a mixed effects analysis of covariance with period, baseline $\mathrm{FEV}_{1}$ by day, treatment by day, and mean baseline $\mathrm{FEV}_{1}$ by day fitted as fixed effects and subject as a random coefficient; adjusted means and treatment differences were calculated along with corresponding $95 \%$ confidence intervals (CIs). Trough $\mathrm{FEV}_{1}$ on Day 2 and trough 
FVC endpoints were analyzed similarly. Prior to analysis, plethysmography parameters (sGaw, Raw, IC, and RV) were $\log _{\mathrm{e}}$-transformed; the transformed parameters were analyzed in the same way as the primary efficacy parameter and back transformed prior to reporting. No formal statistical analysis was performed on safety data except for the maximum, minimum, and weighted mean parameters for 12-lead ECG QTc Fridericia's formula (F) and QTc Bazzett's formula (B) and supine vital signs data, which were analyzed in the same way as the primary efficacy parameter.

The PK parameters were calculated by standard noncompartmental analysis using WinNonlin ${ }^{\circledR}$ Pro (Pharsight, St Louis, MO). Plasma concentration data were listed and summarized (in tabular form as well as mean, median, and individual subject plots on the semilogarithmic and linear scales).

\section{Results \\ Study population}

A total of 47 dually responsive subjects were randomized, received treatment, and comprised the safety population. Four subjects $(8.5 \%)$ were excluded from the MPP population due to failing to complete a baseline and posttreatment assessment for at least one efficacy parameter in at least two periods.

In the MPP population, 23 subjects received GSK233705 $20 \mu \mathrm{g}$ + salmeterol, 27 received GSK233705 $50 \mu \mathrm{g}+$ salmeterol, 27 received salmeterol alone, 28 received tiotropium alone, and 24 received placebo. The mean \% predicted postbronchodilator $\mathrm{FEV}_{1}$ was $55 \%$ at screening and the mean percent reversibilities to ipratropium and salbutamol were $26 \%$ and $23 \%$, respectively. The demographic and baseline characteristics of the safety and MPP study populations are shown in Table 1.

\section{Efficacy}

\section{Primary endpoint}

Trough FEV, on Day 8

Raw mean trough $\mathrm{FEV}_{1}$ on Day 8 was higher for all active treatments than for placebo (Figure 1). All active treatments increased trough $\mathrm{FEV}_{1}$ on Day 8 by more than $120 \mathrm{~mL}$ compared with baseline, whereas the increase after placebo treatment was only $20 \mathrm{~mL}$ (adjusted mean differences).

Compared with placebo, the increase in trough $\mathrm{FEV}_{1}$ was $215 \mathrm{~mL}$ higher with GSK233705 $20 \mu \mathrm{g}+$ salmeterol and $203 \mathrm{~mL}$ higher with GSK233705 $50 \mu \mathrm{g}+$ salmeterol,
Table I Baseline demographics and characteristics of the safety and modified per protocol (MPP) populations

\begin{tabular}{|c|c|c|}
\hline & $\begin{array}{l}\text { Safety population } \\
(N=47)\end{array}$ & $\begin{array}{l}\text { MPP population } \\
(\mathrm{N}=\mathbf{4 3})\end{array}$ \\
\hline \multicolumn{3}{|l|}{ Age (years) } \\
\hline Mean (SD) & $62.6(6.9)$ & $62.3(7.1)$ \\
\hline Range & $47-75$ & $47-75$ \\
\hline \multicolumn{3}{|l|}{ Gender, n (\%) } \\
\hline Female & $18(38 \%)$ & I8 (42\%) \\
\hline Male & $29(62 \%)$ & $25(58 \%)$ \\
\hline \multicolumn{3}{|l|}{ Ethnicity, n (\%) } \\
\hline White & $47(100 \%)$ & $43(100 \%)$ \\
\hline \multicolumn{3}{|l|}{ Body mass index $\left(\mathrm{kg} / \mathrm{m}^{2}\right)$} \\
\hline Mean (SD) & $25.3(2.9)$ & $25.3(3.0)$ \\
\hline Range & $20.2-30.9$ & $20.2-30.9$ \\
\hline \multicolumn{3}{|l|}{ Smoking history } \\
\hline Current/former n (\%) & $23(49 \%) / 24(51 \%)$ & $2 \mathrm{I}(49 \%) / 22(5 \mathrm{I} \%)$ \\
\hline \multicolumn{3}{|l|}{ Years smoked } \\
\hline Mean (SD) & $38.8(8.9)$ & $38.6(9.0)$ \\
\hline Range & $20-60$ & $20-60$ \\
\hline \multicolumn{3}{|l|}{ Number of cigarettes/day } \\
\hline Mean (SD) & $20.5(7.8)$ & $20.7(7.8)$ \\
\hline Range & $5-40$ & $5-40$ \\
\hline \multicolumn{3}{|l|}{ Smoking pack years } \\
\hline Mean (SD) & $40.0(19.2)$ & $40.3(19.4)$ \\
\hline Range & II $.5-90.0$ & II.5-90.0 \\
\hline \multicolumn{3}{|l|}{ Postbronchodilator } \\
\hline \multicolumn{3}{|l|}{ FEV , at screening } \\
\hline \multicolumn{3}{|l|}{$\%$ predicted normal FEV, } \\
\hline Mean (SD) & $55.3(10.5)$ & $54.8(9.5)$ \\
\hline Range & $39.8-84.9$ & $39.8-72.1$ \\
\hline \multicolumn{3}{|l|}{$\%$ reversibility in baseline } \\
\hline \multicolumn{3}{|l|}{ FEV, ipratropium } \\
\hline Mean (SD) & $26.3(11.3)$ & $25.7(10.7)$ \\
\hline Range & $9.3-52.4$ & $9.3-52.4$ \\
\hline \multicolumn{3}{|l|}{ Salbutamol } \\
\hline Mean (SD) & $24.6(11.5)$ & $23.3(9.4)$ \\
\hline Range & $10.6-66.7$ & $10.6-52.7$ \\
\hline \multicolumn{3}{|l|}{ COPD medication } \\
\hline \multicolumn{3}{|l|}{ during treatment } \\
\hline $\mathrm{N}(\%)$ & $37(79 \%)$ & $34(79 \%)$ \\
\hline \multicolumn{3}{|l|}{ Inhaled corticosteroids } \\
\hline$N(\%)$ & $25(53 \%)$ & $23(53 \%)$ \\
\hline
\end{tabular}

Abbreviations: $\mathrm{FEV}_{1}$, forced expiratory volume in I second; SD, standard deviation.

whereas with salmeterol and tiotropium alone the increases were $101 \mathrm{~mL}$ and $118 \mathrm{~mL}$ higher, respectively. Larger increases from baseline in trough $\mathrm{FEV}_{1}$ on Day 8 were also seen with the combination treatments compared with the individual treatments (Table 2). For all treatment comparisons performed, the lower $95 \% \mathrm{CI}$ for the treatment difference was $>0$, giving strong statistical evidence of a benefit of the combination treatments over placebo, salmeterol, and tiotropium, and of salmeterol and tiotropium over placebo (Table 2). 


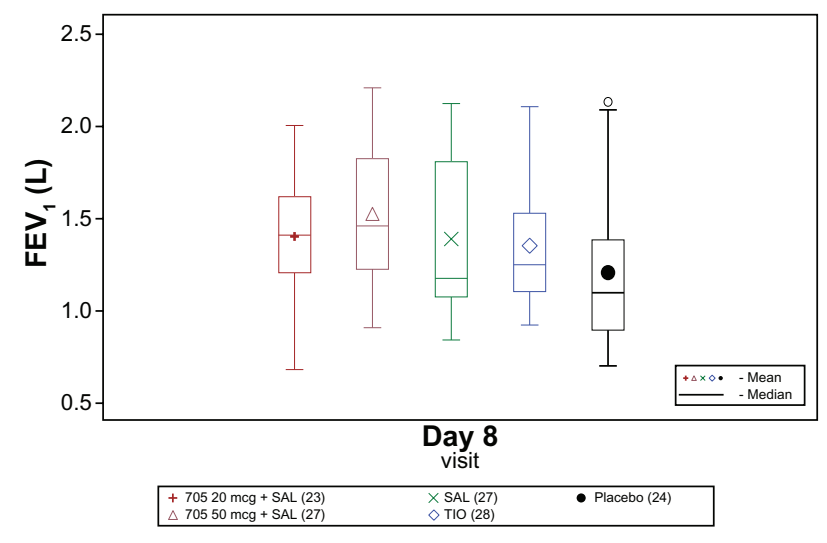

Figure I Box plot of raw mean trough (morning, predose) forced expiratory volume in I second ( $\mathrm{FEV}_{1}$ ) on Day 8 (modified per protocol population). Abbreviations: SAL, salmeterol; TIO, tiotropium.

\section{Secondary endpoints}

Trough FEV, on Day 2

Raw mean trough $\mathrm{FEV}_{1}$ on Day 2 was higher for all active treatments than for placebo (Figure 2), and all treatments increased trough $\mathrm{FEV}_{1}$ on Day 2 compared with baseline. Compared with placebo, the increase from baseline in trough $\mathrm{FEV}_{1}$ was $306 \mathrm{~mL}$ higher with GSK233705 $20 \mu \mathrm{g}+$ salmeterol and $251 \mathrm{~mL}$ higher with GSK233705 $50 \mu \mathrm{g}+$ salmeterol, whereas with salmeterol and tiotropium the increases were $105 \mathrm{~mL}$ and $136 \mathrm{~mL}$ higher, respectively. Larger increases from baseline in trough $\mathrm{FEV}_{1}$ on Day 2 were also seen with the combination treatments compared with the individual treatments: $201 \mathrm{~mL}$ versus salmeterol and $170 \mathrm{~mL}$ versus tiotropium for GSK233705 $20 \mu \mathrm{g}+$ salmeterol and $145 \mathrm{~mL}$ versus salmeterol and $115 \mathrm{~mL}$ versus tiotropium for GSK233705 $50 \mu \mathrm{g}+$ salmeterol.

For all treatment comparisons performed, the lower $95 \%$ CI for the treatment difference was $>0$, giving strong statistical evidence of a benefit of the combination treatments over placebo, salmeterol, and tiotropium, and of salmeterol and tiotropium over placebo (Table 3).

\section{Trough FVC and postdose FVC}

Trough FVC and postdose FVC values followed a similar pattern to that observed for the $\mathrm{FEV}_{1}$ endpoints. Compared with placebo, the change from baseline in trough FVC on Day 8 was $411 \mathrm{~mL}$ higher with GSK233705 $20 \mu \mathrm{g}+$ salmeterol and $355 \mathrm{~mL}$ higher with GSK233705 $50 \mu \mathrm{g}+$ salmeterol, whereas with salmeterol and tiotropium the changes were $144 \mathrm{~mL}$ and $257 \mathrm{~mL}$ higher, respectively. Trough FVC values and treatment differences on Day 2 were generally higher than those recorded on Day 8. For all comparisons of combination treatments and tiotropium with placebo, the lower $95 \% \mathrm{CI}$ for the treatment difference was $>0$, giving strong statistical evidence of a benefit. The evidence was less strong for the benefit of salmeterol over placebo. Correspondingly there was statistical evidence (lower $95 \% \mathrm{CI}>0$ ) of a benefit of combination treatment over salmeterol, but no consistent statistical evidence of a benefit over tiotropium.

All active treatments increased postdose serial $\mathrm{FEV}_{1}$, and postdose FVC relative to placebo at all time points on both days, with the combination treatments again showing an improvement compared with salmeterol alone and tiotropium alone (Figure 3). For all comparisons of combination treatments with placebo, the lower $95 \%$ CI for the ratio between treatments was $>0$, giving strong statistical evidence of a benefit.

\section{Plethysmography}

All active treatments increased trough sGaw on Day 8 by more than $22 \%$ compared with baseline, whereas placebo treatment showed a 3\% decrease from baseline. The ratio to baseline compared with placebo was $49.8 \%$ higher with GSK233705 $20 \mu \mathrm{g}+$ salmeterol and 65.9\% higher with

Table 2 Analysis of trough (morning, predose) forced expiratory volume in I second (L) on Day 8 (modified per protocol population)

\begin{tabular}{|c|c|c|c|c|c|}
\hline & $\begin{array}{l}\text { GSK233705 } 20 \mu \mathrm{g}+ \\
\text { salmeterol }\end{array}$ & $\begin{array}{l}\text { GSK233705 } 50 \mu \mathrm{g}+ \\
\text { salmeterol }\end{array}$ & Salmeterol & Tiotropium & Placebo \\
\hline $\mathrm{n}$ & 22 & 26 & 27 & 28 & 24 \\
\hline Baseline raw mean (SD) & $1.16(0.31)$ & $\mathrm{I} .29(0.43)$ & $\mathrm{I} .29(0.42)$ & $\mathrm{I} .20(0.34)$ & $1.19(0.36)$ \\
\hline Endpoint adjusted mean (SE) & $1.46(0.03)$ & $1.45(0.03)$ & $1.35(0.03)$ & $1.37(0.03)$ & $1.25(0.03)$ \\
\hline Adjusted mean change from baseline (SE) & $0.24(0.03)$ & $0.22(0.03)$ & $0.12(0.03)$ & $0.14(0.03)$ & $0.02(0.03)$ \\
\hline Difference from placebo (SE) & $0.21(0.04)$ & $0.20(0.03)$ & $0.10(0.03)$ & $0.12(0.03)$ & \\
\hline $95 \% \mathrm{Cl}$ & $(0.14,0.29)$ & $(0.13,0.27)$ & $(0.03,0.17)$ & $(0.05,0.18)$ & \\
\hline Difference from salmeterol (SE) & $0.11(0.03)$ & $0.10(0.03)$ & & & \\
\hline $95 \% \mathrm{Cl}$ & $(0.04,0.18)$ & $(0.04,0.17)$ & & & \\
\hline Difference from tiotropium (SE) & $0.10(0.03)$ & $0.08(0.03)$ & & & \\
\hline $95 \% \mathrm{Cl}$ & $(0.03,0.17)$ & $(0.02,0.15)$ & & & \\
\hline
\end{tabular}

Abbreviations: $\mathrm{Cl}$, confidence interval; SD, standard deviation; SE, standard error of the mean. 


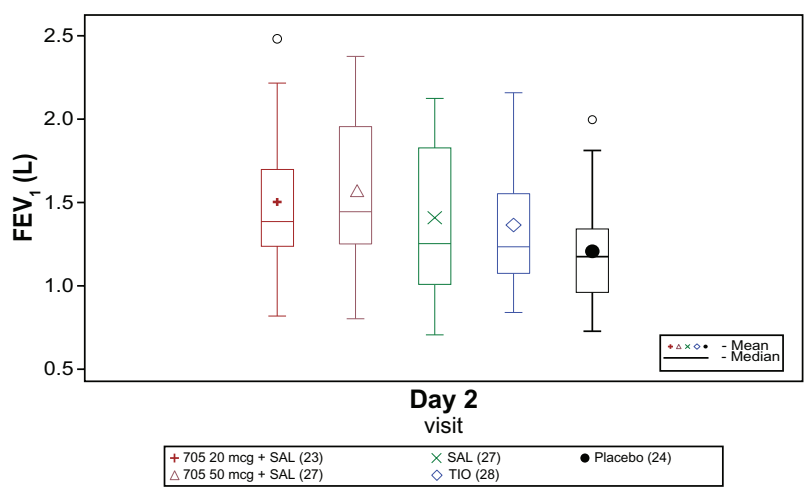

Figure 2 Box plot of raw mean trough (morning, predose) forced expiratory volume in I second ( $\mathrm{FEV}_{1}$ ) on Day 2 (modified per protocol population).

Abbreviations: SAL, salmeterol; TIO, tiotropium.

GSK233705 $50 \mu \mathrm{g}+$ salmeterol, whereas with salmeterol and tiotropium bromide the ratios were $26.6 \%$ and $29.8 \%$ higher, respectively.

Postdose sGaw, trough Raw, and postdose Raw also reflected the spirometric results (as did IC and RV to a lesser extent) (Table 4).

\section{Morning PEF}

The combination treatments both increased PEF by approximately $35 \mathrm{~L} /$ min compared with placebo whereas salmeterol and tiotropium increased PEF by $20 \mathrm{~L} / \mathrm{min}$ and $15 \mathrm{~L} / \mathrm{min}$, respectively. For all treatment comparisons performed, the lower $95 \%$ CI for the treatment difference was $>0$, indicating strong statistical evidence of a benefit of the combination treatments over placebo, salmeterol and tiotropium, and of salmeterol and tiotropium over placebo.

\section{Rescue use}

For subjects receiving GSK233705 $20 \mu \mathrm{g}+$ salmeterol and GSK233705 $50 \mu \mathrm{g}+$ salmeterol, $52.4 \%$, and $46.2 \%$ never needed to use their salbutamol rescue medication during the treatment period, compared with $44.4 \%$ of subjects receiving salmeterol, $32.1 \%$ of subjects receiving tiotropium, and $16.7 \%$ of subjects receiving placebo.

\section{Safety}

AEs

The safety profiles were similar across all treatments. The most common AEs with onset while on-treatment were headache and ventricular extrasystoles (Table 5). Headache was the most frequently reported treatment-related $\mathrm{AE}$ and was reported by one subject on each of GSK233705 $20 \mu \mathrm{g}+$ salmeterol, tiotropium, and placebo. No serious AEs were reported in treated subjects. Four subjects were withdrawn; three due to an exacerbation (two following treatment with placebo and one after salmeterol) and one subject on salmeterol treatment had an $\mathrm{AE}$ of nonsustained ventricular tachycardia ( $<30$ beats), which led to withdrawal from the study.

\section{Vital signs}

The changes in heart rate from baseline on Day 1 and Day 7 were similar for all treatments including placebo. There was some evidence of a small increase in heart rate on salmeterol compared with placebo on Day 1, with lower CIs above zero for the comparisons of both weighted mean and maximum heart rate over 0-24 hours. Similar evidence was seen for a decrease in heart rate on the combination treatments compared with salmeterol, with upper CIs $<0$ for the comparison of each combination treatment with salmeterol for weighted mean and minimum heart rate, and for the comparison of GSK233705 $50 \mu \mathrm{g}+$ salmeterol with salmeterol for maximum heart rate. These differences were small, with maximum and minimum $95 \%$ CIs less than $\pm 6.4 \mathrm{bpm}$. However, similar evidence was not seen on Day 7.

Table 3 Analysis of trough (morning, predose) forced expiratory volume in I second (L) on Day 2 (modified per protocol population)

\begin{tabular}{|c|c|c|c|c|c|}
\hline & $\begin{array}{l}\text { GSK233705 } 20 \mu \mathrm{g}+ \\
\text { salmeterol }\end{array}$ & $\begin{array}{l}\text { GSK233705 } 50 \mu \mathrm{g}+ \\
\text { salmeterol }\end{array}$ & Salmeterol & Tiotropium & Placebo \\
\hline $\mathrm{n}$ & 23 & 27 & 27 & 28 & 24 \\
\hline Baseline raw mean (SD) & $1.18(0.32)$ & $1.29(0.42)$ & $1.29(0.42)$ & $1.20(0.34)$ & $1.19(0.36)$ \\
\hline Endpoint adjusted mean (SE) & $1.55(0.03)$ & $1.49(0.03)$ & $1.34(0.03)$ & $1.37(0.03)$ & $\mathrm{I} .24(0.03)$ \\
\hline Adjusted mean change from baseline (SE) & $0.32(0.03)$ & $0.23(0.028)$ & $0.12(0.03)$ & $0.15(0.03)$ & $0.01(0.03)$ \\
\hline Difference from placebo (SE) & $0.31(0.04)$ & $0.25(0.04)$ & $0.10(0.04)$ & $0.14(0.037)$ & \\
\hline $95 \% \mathrm{Cl}$ & $(0.23,0.38)$ & $(0.17,0.33)$ & $(0.03,0.18)$ & $(0.06,0.21)$ & \\
\hline Difference from salmeterol (SE) & $0.20(0.04)$ & $0.14(0.04)$ & & & \\
\hline $95 \% \mathrm{Cl}$ & $(0.12,0.28)$ & $(0.07,0.22)$ & & & \\
\hline Difference from tiotropium (SE) & $0.17(0.04)$ & $0.11(0.04)$ & & & \\
\hline $95 \% \mathrm{Cl}$ & $(0.09,0.25)$ & $(0.04,0.19)$ & & & \\
\hline
\end{tabular}

Abbreviations: $\mathrm{Cl}$, confidence interval; SD, standard deviation; $\mathrm{SE}$, standard error of the mean. 


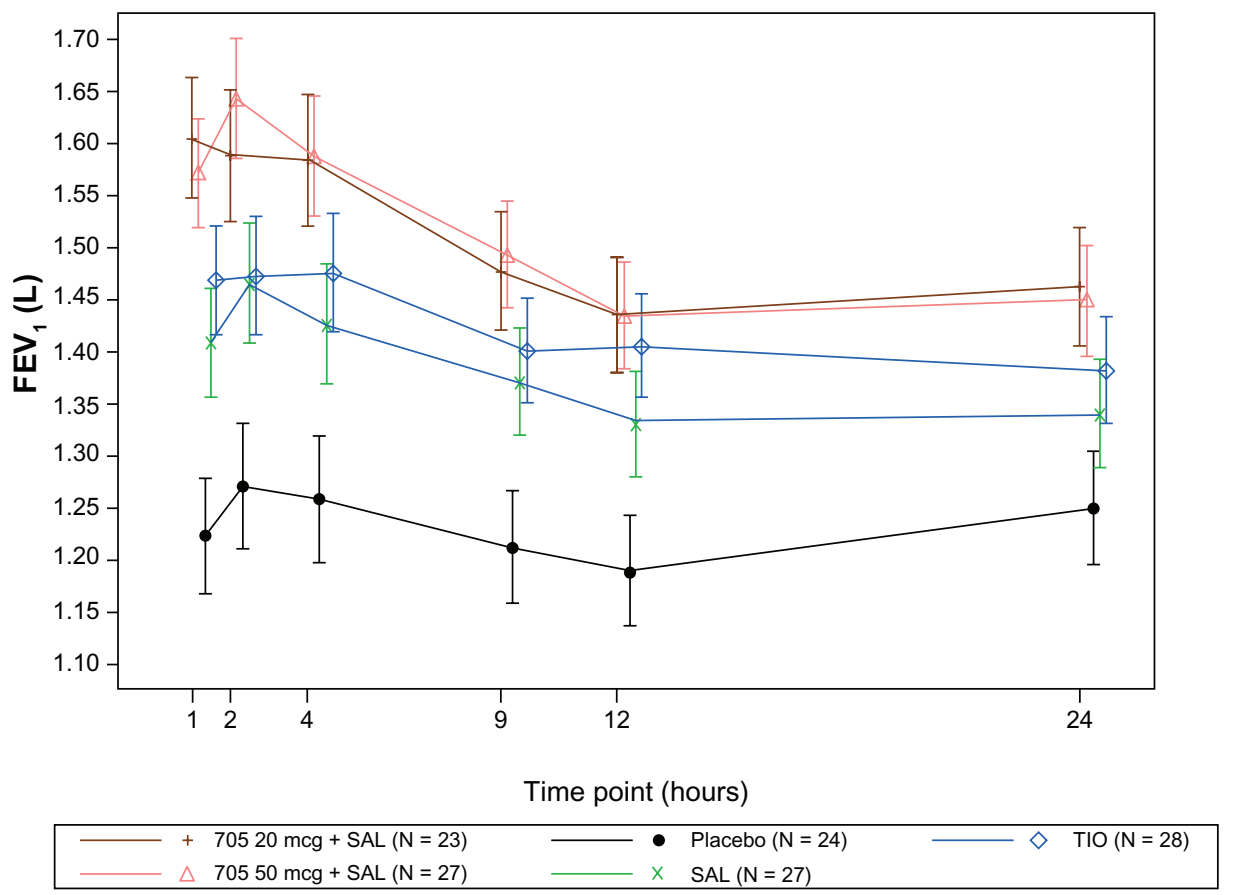

Figure 3 Adjusted mean ( $95 \%$ confidence interval) forced expiratory volume in I second (FEV $)$ over time on Day 7 (modified per protocol population). Abbreviations: SAL, salmeterol; TIO, tiotropium.

Table 4 Trough sGaw, Raw, IC, and RV on Day 2 and Day 8 (modified per protocol population)

\begin{tabular}{|c|c|c|c|c|c|}
\hline & GSK233705 & GSK233705 & Salmeterol & Tiotropium & Placebo \\
\hline & $20 \mu \mathrm{g}+$ salmeterol & $50 \mu \mathrm{g}+$ salmeterol & & & \\
\hline \multicolumn{6}{|l|}{ Day 2} \\
\hline$n$ & 23 & 27 & 27 & 27 & 24 \\
\hline \multicolumn{6}{|l|}{ Trough sGaw } \\
\hline Endpoint adjusted geometric mean & 0.79 & 0.84 & 0.56 & 0.59 & 0.47 \\
\hline Ratio of individual treatments to placebo $(95 \% \mathrm{Cl})$ & $1.68(1.48,1.91)$ & $1.77(1.57,2.00)$ & $1.19(1.05,1.35)$ & $1.26(1.11,1.42)$ & \\
\hline \multicolumn{6}{|l|}{ Trough Raw } \\
\hline Endpoint adjusted geometric mean & 0.26 & 0.25 & 0.36 & 0.33 & 0.42 \\
\hline Ratio of individual treatments to placebo $(95 \% \mathrm{Cl})$ & $0.62(0.54,0.70)$ & $0.60(0.53,0.67)$ & $0.86(0.76,0.97)$ & $0.80(0.7 I, 0.90)$ & \\
\hline \multicolumn{6}{|l|}{ Trough IC } \\
\hline Endpoint adjusted geometric mean & 2.25 & 2.17 & 2.01 & 2.09 & 1.98 \\
\hline Ratio of individual treatments to placebo $(95 \% \mathrm{Cl})$ & $1.13(1.06,1.21)$ & $1.09(1.03,1.16)$ & $1.02(0.96,1.08)$ & $1.06(0.99,1.12)$ & \\
\hline \multicolumn{6}{|l|}{ Trough RV } \\
\hline Endpoint adjusted geometric mean & 3.02 & 3.06 & 3.31 & 3.32 & 3.57 \\
\hline Ratio of individual treatments to placebo $(95 \% \mathrm{Cl})$ & $0.85(0.78,0.92)$ & $0.857(0.79,0.93)$ & $0.93(0.85,1.01)$ & $0.932(0.86,1.01)$ & \\
\hline \multicolumn{6}{|l|}{ Day 8} \\
\hline $\mathrm{n}$ & 21 & 26 & 27 & 28 & 24 \\
\hline \multicolumn{6}{|l|}{ Trough sGaw } \\
\hline Endpoint adjusted geometric mean & 0.66 & 0.73 & 0.56 & 0.57 & 0.44 \\
\hline Ratio of individual treatments to placebo $(95 \% \mathrm{Cl})$ & $1.50(1.31,1.70)$ & $1.66(1.47,1.87)$ & $1.27(1.12,1.43)$ & $1.30(1.15,1.47)$ & \\
\hline \multicolumn{6}{|l|}{ Trough Raw } \\
\hline Endpoint adjusted geometric mean & 0.31 & 0.29 & 0.36 & 0.35 & 0.44 \\
\hline Ratio of individual treatments to placebo $(95 \% \mathrm{Cl})$ & $0.7 \mathrm{I}(0.62,0.8 \mathrm{I})$ & $0.65(0.58,0.74)$ & $0.81(0.72,0.92)$ & $0.80(0.71,0.91)$ & \\
\hline \multicolumn{6}{|l|}{ Trough IC } \\
\hline Endpoint adjusted geometric mean & 2.16 & 2.17 & 2.03 & 2.07 & 1.93 \\
\hline Ratio of individual treatments to placebo $(95 \% \mathrm{Cl})$ & $1.12(1.04,1.20)$ & $1.12(1.05,1.20)$ & $1.05(0.98,1.12)$ & $1.07(1.00,1.14)$ & \\
\hline \multicolumn{6}{|c|}{ Trough RV } \\
\hline Endpoint adjusted geometric mean & 3.03 & 3.03 & 3.33 & 3.31 & 3.59 \\
\hline Ratio of individual treatments to placebo $(95 \% \mathrm{Cl})$ & $0.84(0.79,0.90)$ & $0.84(0.79,0.90)$ & $0.93(0.87,0.98)$ & $0.92(0.87,0.98)$ & \\
\hline
\end{tabular}

Abbreviations: $\mathrm{Cl}$, confidence interval; IC, inspiratory capacity; Raw, airways resistance; $\mathrm{RV}$, residual volume; sGaw, plethysmography parameters airway conductance. 
Table 5 Adverse events (AEs) with onset on-treatment experienced by more than one subject on any treatment (safety population)

\begin{tabular}{|c|c|c|c|c|c|}
\hline AE n (\%) & $\begin{array}{l}\text { GSK233705 } 20 \mu \mathrm{g}+ \\
\text { salmeterol }(\mathbf{N}=23)\end{array}$ & $\begin{array}{l}\text { GSK233705 } 50 \mu \mathrm{g}+ \\
\text { salmeterol }(\mathbf{N}=27)\end{array}$ & $\begin{array}{l}\text { Salmeterol } \\
(\mathbf{N}=29)\end{array}$ & $\begin{array}{l}\text { Tiotropium } \\
(\mathbf{N}=\mathbf{2 8})\end{array}$ & $\begin{array}{l}\text { Placebo } \\
(N=26)\end{array}$ \\
\hline Subjects with any $A E$ & 14 (6I\%) & II (4I\%) & $16(55 \%)$ & $16(57 \%)$ & $12(46 \%)$ \\
\hline Nasopharyngitis & I (4\%) & 0 & I (3\%) & I (4\%) & $2(8 \%)$ \\
\hline Urinary tract infection & I (4\%) & 0 & I (3\%) & $\mathrm{I}(4 \%)$ & $2(8 \%)$ \\
\hline Influenza & $2(9 \%)$ & 0 & 0 & $2(7 \%)$ & 0 \\
\hline Headache & $4(17 \%)$ & $2(7 \%)$ & $2(7 \%)$ & $5(18 \%)$ & $3(11 \%)$ \\
\hline Dizziness & $\mathrm{I}(4 \%)$ & $2(7 \%)$ & 0 & $\mathrm{I}(4 \%)$ & 0 \\
\hline Ventricular extrasystoles & I (4\%) & I (4\%) & $3(10 \%)$ & I (4\%) & 0 \\
\hline Ventricular tachycardia & I (4\%) & 0 & $2(7 \%)$ & I (4\%) & 0 \\
\hline Supraventricular tachycardia & I (4\%) & 0 & 0 & $2(7 \%)$ & 0 \\
\hline Supraventricular extrasystoles & 0 & 0 & $2(7 \%)$ & 0 & 0 \\
\hline Back pain & 0 & 0 & $2(7 \%)$ & 0 & $3(11 \%)$ \\
\hline Leukocyturia & 0 & $2(7 \%)$ & 0 & I (4\%) & 0 \\
\hline Fatigue & 0 & 0 & 0 & I (4\%) & $2(8 \%)$ \\
\hline
\end{tabular}

The changes in systolic and diastolic blood pressure from baseline on Day 1 and Day 7 were similar between all treatments including placebo. Treatment differences for weighted mean, maximum and minimum systolic and diastolic blood pressure over 0-4 hours and 0-24 hours were small, and in all cases except one the CIs for all treatment comparisons contained zero.

\section{ECGs}

No clinically significant changes in ECG traces during any visit postbaseline were reported for any treatment. Summary statistics for Holter ECG parameters (maximum, mean and minimum heart rate, maximum and mean uncorrected QT, maximum RR, mean QTc(B) and QTc(F), number of RR intervals $>2 \mathrm{msec}$, and number of ventricular couplets, triplets and nonsustained ventricular tachycardias, and supraventricular tachycardias) were similar for all treatments at screening and on Day 1 and Day 7.

\section{Pharmacokinetics}

The bioanalytical method (LLQ of $0.01 \mathrm{ng} / \mathrm{mL}$ ) for GSK233705 was not sensitive enough to fully characterize the PK profile of subjects due to the low level of GSK233705 detected in plasma. Overall, $52 \%$ of data were nonquantifiable. Following single and repeat inhaled dose administration, GSK233705 was rapidly absorbed. The median $t_{\text {max }}$ was 5 minutes, irrespective of dose levels ( $20 \mu \mathrm{g}$ and $50 \mu \mathrm{g})$ and sampling days (Day 1 and Day 7). Plasma concentrations declined rapidly following the occurrence of $\mathrm{C}_{\max }$. Plasma concentrations following repeat inhaled administration were on average higher than those after single dosing for both dose levels suggestive of accumulation. Moderate to high between-subject variability in $\mathrm{C}_{\max }$ was observed with values of the coefficient of variation ranging from $42 \%$ to $60 \%$ on Day 1 , and from $42 \%$ to $52 \%$ on Day 7 across dose levels. Moderate to high between-subject variability in $\mathrm{AUC}_{(0-\mathrm{t})}$ was also observed with values of the coefficient of variation ranging from $29 \%$ to $67 \%$ on Day 1, and from $98 \%$ to $130 \%$ on Day 7 across dose levels (Table 6).

The bioanalytical method (LLQ of $0.025 \mathrm{ng} / \mathrm{mL}$ ) for salmeterol was not sensitive enough to fully characterize the PK profile of subjects due to the low level of salmeterol detected in plasma. For salmeterol, overall 55\% (604/1092) of data was nonquantifiable. The median $\mathrm{t}_{\max }$ was 30 minutes or less irrespective of sampling day or whether salmeterol was administered alone or in combination with GSK233705. Moderate between-subject variability in $\mathrm{C}_{\max }$ was observed with values of the coefficient of variation ranging from $29 \%$ to $38 \%$ on Day 1 , and from $41 \%$ to $53 \%$ on Day 7 across treatment regimens. Moderate to high between-subject variability in $\mathrm{AUC}_{(0-t)}$ was also observed with values of the coefficient of variation ranging from $35 \%$ to $54 \%$ on Day 1 , and from $68 \%$ to $124 \%$ on Day 7 across treatment regimens.

\section{Discussion}

The objectives of this pilot study were to investigate the bronchodilatory efficacy, safety, and tolerability of twice-daily therapy with two different long-acting bronchodilators in a COPD population optimized to demonstrate a response. These were administered concurrently (GSK233705 + salmeterol) and compared primarily with placebo but also compared with twice-daily salmeterol monotherapy or once-daily tiotropium monotherapy in subjects with moderate to severe COPD. The primary lung function measurements were made using spirometry, and this was supported by plethysmography, which provides a further sensitive assessment of lung 


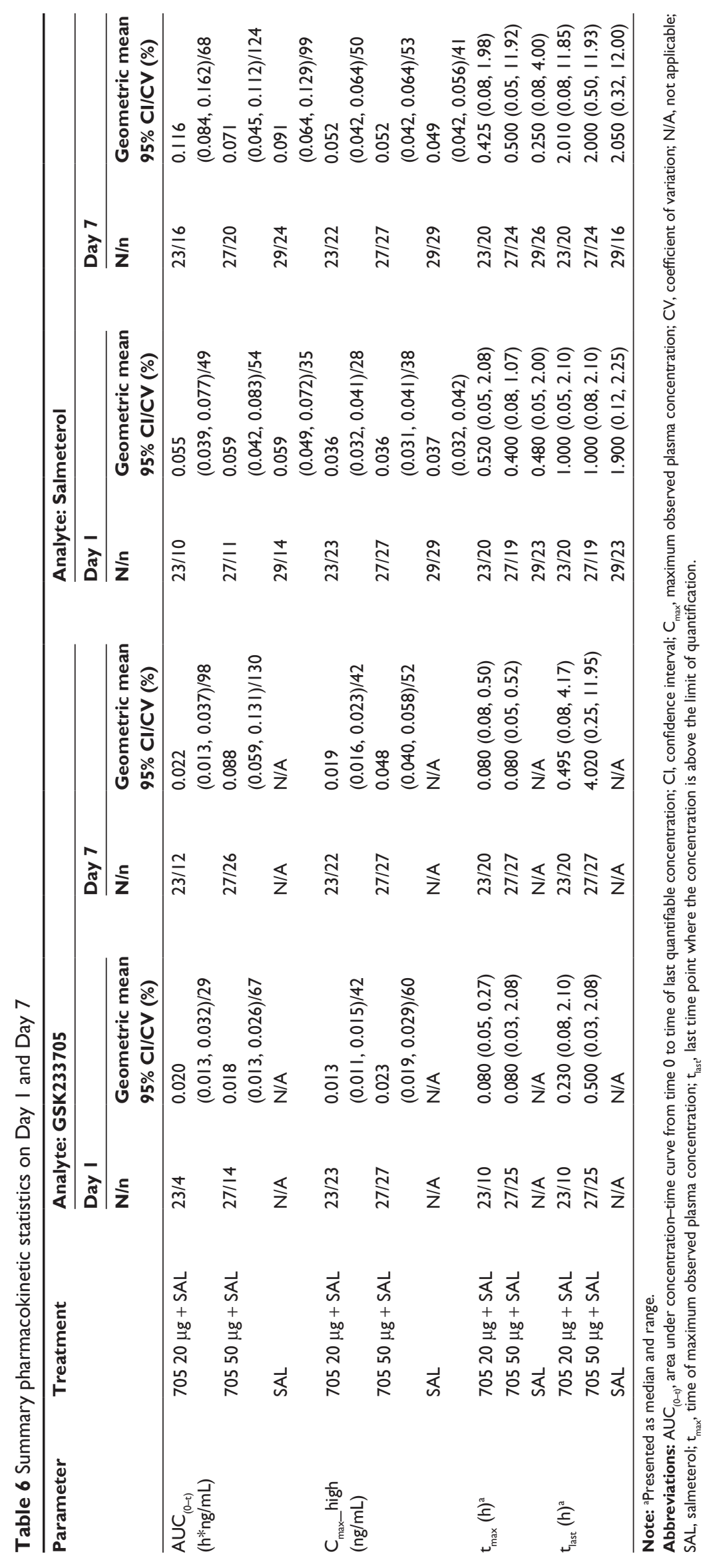


function $^{16}$ and also takes into account effects on both the large and small airways.

A crossover design was chosen because the within-patient variability in $\mathrm{FEV}_{1}$ was expected to be less than betweenpatient variability, with each patient acting as their own control. An incomplete-block, rather than a complete-block, crossover design was adopted (with three periods) to reduce the study duration and overall burden on patients. To fully blind the study, each subject would have needed to use both inhalers on a double-dummy basis and to take multiple inhalations morning and evening. In order to reduce the number of inhalers subjects needed to take daily, the study was blinded for active versus placebo treatments but not with respect to inhaler type. The duration of 2 weeks for washout was also sufficient to minimize the possibility of carry-over effects of both salmeterol and tiotropium. It is recognized however that a limitation of the study was that there was no GSK233705 monotherapy arm.

Concurrent use of GSK233705 at doses of $20 \mu \mathrm{g}$ or $50 \mu \mathrm{g}$ twice-daily plus salmeterol $50 \mu \mathrm{g}$ twice-daily for 7 days resulted in clinically important improvements in lung function which were greater than those seen with placebo, salmeterol $50 \mu \mathrm{g}$ twice-daily alone, or tiotropium $18 \mu \mathrm{g}$ once-daily alone. The improvement versus placebo in bronchodilation with both doses of GSK233705 plus salmeterol was not only higher than the $100 \mathrm{~mL}$ criterion described by Donohue ${ }^{17}$ as a difference that COPD patients can perceive but also was well above the range $(100-140 \mathrm{~mL})$ proposed as a minimal clinically important difference. ${ }^{18}$

The clinical improvements seen in lung function were also supported by the results of daily diary card assessments, morning PEF measurements, and rescue medication use, all of which suggested that dual bronchodilator treatment has the potential to produce a clinically important additional benefit on symptoms compared with a single agent. It has previously been shown that these two classes of bronchodilator added together result in a significant reduction in salbutamol use as rescue therapy and symptoms of dyspnoea. ${ }^{5,19}$ This study provides further support for these observations. Although this study did not include symptom assessments, the need for rescue medication is a useful surrogate of symptomatic benefit and reductions in the use of rescue medication were seen with the combination treatments compared with each of the individual treatments.

The positive primary efficacy results were supported by the results from all of the remaining lung function assessments.

Although this was a small study, and the endpoints not formally powered, the results were consistent across virtually every endpoint studied and the sizes of the treatment differences were compelling. No obvious dose response was observed between the two doses of GSK233705 in combination with salmeterol for any of the endpoints, but the study was not designed to differentiate between doses.

The safety findings from this study demonstrated that the safety profiles were similar across all treatments. No clinically significant effects on heart rate were observed with concurrent administration of GSK233705 and salmeterol and, importantly, analysis of 24-hour Holter ECG measurements did not identify any change in the incidence of the minor rhythm abnormalities frequently observed in COPD patients.

The pharmacokinetic information obtained in this study was limited due to a large amount of nonquantifiable data. However, the results showed that, following single and repeat inhaled doses, there was rapid absorption of both GSK233705 and salmeterol with a median time to $\mathrm{C}_{\max }\left(\mathrm{t}_{\max }\right)$ of 5 minutes for GSK233705 and 30 minutes for salmeterol. The PK parameters for salmeterol were similar in the presence and absence of GSK233705, demonstrating an absence of any PK interaction between the two drugs.

Results from this study support previous findings which have demonstrated that a long-acting $\beta$-agonist added to a long-acting anticholinergic (tiotropium bromide) produce incremental effects on lung function. Data from both shortterm ${ }^{4-6,16}$ and long-term studies provide additional evidence that combining LAMAs and LABAs helps to maximize bronchodilation and improve symptoms and quality of life in patients with moderate to severe disease..$^{7-8,20}$ Importantly, in this study no increase in the risk of side effects was observed with the combinations compared with monotherapies.

Most subjects recruited for this study had moderate disease and were documented to demonstrate significant bronchodilator responses to both anticholinergics and $\beta_{2}$-agonists. This further supports the use of LABA/LAMA combination therapy in moderate COPD if maintenance treatment with a single long-acting bronchodilator does not suffice. ${ }^{1-3}$ Published evidence to date also supports the use of a combination therapy with tiotropium plus a LABA even in those COPD patients with more severe symptoms. ${ }^{8,21,22}$ However, limited analyses have been performed to date to assess the differential effects of LAMA therapy by severity of COPD. Clinical studies have included patients with disease severity ranging from moderate to very severe disease. Tashkin et $\mathrm{al}^{6}$ found that while improvements in lung function were greater in more severe COPD, dyspnea scores improved irrespective of severity. 
It has been hypothesized that activity of the sympathetic system is more prominent during the day, whereas increased parasympathetic system activity is found during the night..$^{21-25}$ It therefore seems appropriate to target bronchoconstriction through two distinct mechanisms (anticholinergic and sympathomimetic) to maximize the bronchodilator response over 24 hours and help to overcome inter- and intra-patient variability in bronchomotor tone associated with COPD. ${ }^{26}$

A range of once and twice daily LAMAs are currently in clinical development as monotherapies in COPD. ${ }^{9,10}$ A number of novel once-daily fixed-dose combination bronchodilators are also in phase III development, including QVA149 (a combination of indacaterol and NVA237) ${ }^{27}$ and vilanterol plus GSK573719.28

\section{Conclusion}

This study helps to demonstrate that combinations of these two classes of medications can achieve significant bronchodilation compared to monotherapy. The addition of GSK233705 to salmeterol resulted in greater bronchodilatation than salmeterol or tiotropium alone and was well tolerated. This particular bronchodilator combination is at present not being progressed further because once-daily alternatives are favored and being developed.

\section{Acknowledgments}

The authors thank the patients who took part and the staff at the participating clinical centers. The authors would also like to thank Diana Jones of Cambrian Clinical Associates Limited, a professional medical writer sponsored by GSK, for her assistance in the preparation of this manuscript.

\section{Authors' contributions}

Amanda Deans, Jean Brooks, Claire Maden, Suus Baggen, Rashmi Mehta, and Anthony Cahn (as employees of the study sponsor, GSK) contributed to the design, analysis, and interpretation of the study, and oversaw its conduct. All authors contributed equally to the development of the manuscript, and approved the final version for submission.

\section{Disclosure}

This study was funded by GSK, Stockley Park, UK. Amanda Deans, Jean Brooks, Claire Maden, Suus Baggen, Rashmi Mehta, and Anthony Cahn are employees of GSK. Jutta Beier has given presentations at symposia sponsored by Almirall, Novartis, and Revotar and has received fees for consulting from Almirall, Cytos, Novartis, Pfizer, and Revotar.
Jan van Noord has given presentations at symposia sponsored by AstraZeneca, Boehringer Ingelheim, and GSK, and has received fees for contract research from AstraZeneca, Boehringer Ingelheim, and GSK.

\section{References}

1. Global initiative for chronic Obstructive Lung Disease. Global strategy for the diagnosis, management, and prevention of chronic obstructive pulmonary disease [updated 2008]. Available from: http://www. goldcopd.com. Accessed December 8, 2011.

2. Celli BR, MacNee W. Standards for the diagnosis and treatment of patients with COPD: a summary of the ATS/ /ERS position paper. Eur Respir J. 2004;23(6):932-946.

3. Tashkin DP, Cooper CB. The role of long-acting bronchodilators in the management of stable COPD. Chest. 2004;125(1):249-259.

4. van Noord JA, Aumann JL, Janssens E, et al. Comparison of tiotropium once daily, formoterol twice daily and both combined once daily in patients with COPD. Eur Respir J. 2005;26(2):214-222.

5. van Noord JA, Aumann JL, Janssens E, et al. Effects of tiotropium with and without formoterol on airflow obstruction and resting hyperinflation in patients with COPD. Chest. 2006;129(3):509-517.

6. Tashkin DP, Donohue JF, Mahler DA, et al. Effects of arformoterol twice daily, tiotropium once daily, and their combination in patients with COPD. Respir Med. 2009;103(4):516-524.

7. Vogelmeier C, Kardos P, Harari S, Gans SJ, Stenglein S, Thirlwell J. Formoterol mono- and combination therapy with tiotropium in patients with COPD: a 6-month study. Respir Med. 2008;102(11): 1511-1520.

8. Aaron SD, Vandemheen KL, Fergusson D, et al. Tiotropium in combination with placebo, salmeterol,or fluticasone-salmeterol for treatment of chronic obstructive pulmonary disease: a randomized trial. Ann Intern Med. 2007;146(8):545-555.

9. Cazzola M, Molimard M. The scientific rationale for combining long-acting b2-agonistsandmuscarinic antagonists in COPD. Pulm Pharmacol Ther. 2010;23(4):257-267.

10. Laine DI. Long-acting muscarinic antagonists for the treatment of chronic obstructive pulmonary disease. Expert Rev Clin Pharmacol. 2010;3(1):43-53.

11. Rabe KF, Timmer W, Sagkriotis A, Viel K. Comparison of a combination of tiotropium plus formoterol to salmeterol plus fluticasone in moderate COPD. Chest. 2008;134(2):255-262.

12. Cazzola M, Santus P, Verga M, et al. The functional impact of adding salmeterol to tiotropium in patients with stable COPD. Respir Med. 2004;98(12):1214-1221.

13. van Noord JA, de Munck DR, Bantje TA, et al. Long-term treatment of chronic obstructive pulmonary disease with salmeterol and the additive effect of ipratropium. Eur Respir J. 2000;15(5):878-885.

14. D’Urzo AD, De Salvo MC, Ramirez-Rivera A, et al. In patients with COPD, treatment with a combination of formoterol and ipratropium is more effective than a combination of salbutamol and ipratropium: a 3-week, randomized, double-blind, within-patient, multicenter study. Chest. 2001;119(5):1347-1356.

15. GlaxoSmithKline. Safety and efficacy of GSK233705 plus salmeterol compared with 2 active comparators and placebo in subjects with chronic obstructive pulmonary disease (COPD). In: ClinicalTrials.gov [website on the Internet]. Bethseda, MD: US National Library of Medicine; 2011 [updated March 17, 2011]. Available from: http://clinicaltrials.gov/ ct2/show/NCT00422604. NLM identifier: NCT00422604. Accessed December 15, 2011

16. Singh D, Tal-Singer R, Faiferman I, et al. Plethysmography and impulse oscillometry assessment of tiotropium and ipratropium bromide; a randomized, double-blind, placebo-controlled, cross-over study in healthy subjects. Br J Clin Pharmacol. 2006;61(4):398-404.

17. Donohue JF. Minimal clinically important differences in COPD lung function. COPD. 2005;2(1):111-124. 
18. Cazzola M, MacNee W, Martinez FJ, et al. Outcomes for COPD pharmacological trials: from lung function to biomarkers. Eur Respir J. 2008;31(2):416-469.

19. Van Noord J, Aumann L, Janssens E, Smeets J, Mueller A, Cornelissen P. Combination therapy of tiotropium plus salmeterol superior to single agent therapy in terms of dyspnea improvement in COPD [abstract]. Chest. 2005;128:177S.

20. Tashkin D, Pearle J, Iezzoni D, Varghese ST. Formoterol and tiotropium compared with tiotropium alone for treatment of COPD. COPD. 2009;6(1):17-25.

21. Singh D, Brooks J, Hagan G, Cahn A, O'Connor BJ. Superiority of "triple" therapy with salmeterol/fluticasone propionate and tiotropium bromide versus individual components in moderate to severe COPD. Thorax. 2008;63(7):592-598.

22. Cazzola M, Andò F, Santus P, et al. A pilot study to assess the effects of combining fluticasone propionate/salmeterol and tiotropium on the airflow obstruction of patients with severe-to-very severe COPD. Pulm Pharmacol Ther. 2007;20(5):556-561.

23. Postma DS, Keyzer JJ, Koeter GH, Sluiter HJ, DeVries K. Influence of the parasympathetic and sympathetic nervous system on nocturnal bronchial obstruction. Clin Sci (Lond). 1985;69(3):251-258.
24. Gaultier C, Reinberg A, Girard E. Circadian rhythms in lung resistance and dynamic lung compliance of healthy children. Effects of two bronchodilators. Respir Physiol. 1977;31(2):169-182.

25. Furlan R, Guzzetti S, Crivellaro W, et al. Continuous 24-hour assessment of the neural regulation of systemic arterial pressure and $\mathrm{RR}$ variabilities in ambulant subjects. Circulation. 1990;81(2):537-547.

26. Cazzola M, Tashkin DP. Combination of formoterol and tiotropium in the treatment of COPD: effects on lung function. COPD. 2009;6(5): $404-415$.

27. van Noord JA, Buhl R, LaForce C, et al. QVA149 demonstrates superior bronchodilation compared with indacaterol or placebo in patients with chronic obstructive pulmonary disease. Thorax. 2010;65(12):1086-1091.

28. GlaxoSmithKline. Safety, tolerability, pharmacokinetics and pharmacodynamics of the combination of GSK573719 and GW642444 in subjects with COPD. In: ClinicalTrials.gov [Internet]. Bethesda, MD: National Library of Medicine (US). December 23, 2009 [last updated on May 13, 2010]. Available from: http://clinicaltrials.gov/ct2/show/ NCT01039675. NLM identifier: NCT01039675.

\section{Publish your work in this journal}

The International Journal of COPD is an international, peer-reviewed journal of therapeutics and pharmacology focusing on concise rapid reporting of clinical studies and reviews in COPD. Special focus is given to the pathophysiological processes underlying the disease, intervention programs, patient focused education, and self management protocols.

\section{Dovepress}

This journal is indexed on PubMed Central, MedLine and CAS. The manuscript management system is completely online and includes a very quick and fair peer-review system, which is all easy to use. Visit http://www.dovepress.com/testimonials.php to read real quotes from published authors. 